International Journal of Business Information Systems Strategies (IJBISS) Volume 3, Number 2, May 2014

\title{
Mathematical Assessment of "Blogging Effect" on Consumer Buying Behavior
}

\author{
Dr Riktesh Srivastava \\ Associate Professor, Information Systems \\ Skyline University College, Sharjah.
}

\begin{abstract}
The Internet has escorted in mammothalterations in the marketing strategy by coalescing many diversities of business models involving affiliate marketing, direct sales, viral marketing and marketing online. It has been evidenced that blogs play an imperative role in facilitating customers to form a buying decision. In fact, blogs have an upshot on purchase behavior far more than the social networking platforms. Blogs have unremittingly garnered a reliable audience. When the demonstrative bond between the blogger and the consumers gets very substantial, it can lead the latter to really build a buying decision. The impact of blogs is so intense that it is sometimes stated as "Blogging Effect" on buying behavior. The present study is an endeavor to derive the two important mathematical instigation of the "blogging effect"-
\end{abstract}

1) To determine the average numbers of customers who purchases the products after reading the blog, $_{\text {AvgCust }}(n)$, and

2) Average time (in seconds) the customer takes to read the blogs, AvgWait(t).

The study can be a channeled cradle for companies who are expending blogs as one of the medium for online marketing.

Keywords:

AvgCust(n), AvgWait(t), Blogging effect, Consumer Buying Behavior (CBB), Consumer buying cycle $(C B C)$.

\section{Introduction}

In today's world of marketing, internet and social media play an imperative role in aiding shoppers find the stuffs they are eyeing for. It is indispensably vital that companies have a buoyant existence in the social media podia, otherwise the target audience can effortlessly change sellers. Such is the impact of blogs on consumer and their purchase decisions, that the effect is often dubbed as "Blogging Effect". (Chaffey, Ellis-Chadwick, Johnston \& Mayer, 2006) defines "Blogging Effect" as the methodology by which the consumers can easily and regularly publish experiences on web pages, which are best described as online journals, diaries or news events listings. (Alasilta, A., 2009) mentions blogs as an online page, where the text and/or multimedia can be published.

Since the last 5 years, unfold of social media has further amended buying and selling systems. With platforms like Facebook, Twitter and YouTube, shoppers are ready to dictum their DOI : 10.14810/ijbiss.2014.3201 
experiences with merchandise and companies and to share them with their networks. This has directed to the mounting requisite for companies to engender positive client involvements so as to attenuate the negative articulated messages, which might simply be revealed among the social media platforms to diverse, the potential customers.

The traditional Consumer Buying Behavior (CBB) model proposed by (Kotler, P. 2000) is a set of linear transactions of the various stages of consumers before buying the product. The model is no longer effective for current trends of marketing, wherein, the companies go about their business and interact with individuals.A tremendous amount of datais created by usage of Social media sites, smartphones, and other consumer devices have allowed billions of individuals around the world to sharethe information with others (Chui and Manyika, 2011). As indicated by (Sergio Zyman, 2000), "The era of marketing as we have known it is over, dead, kaput - and most marketers don't realize it".(Sergio Zyman, 2000) further clarifies that technology has given people many more options than they had in the past and has created a consumer democracy in which people around the world constantly use social-media platforms to seek and share information from discussing consumer products to organizing political movements.

Enduring to the study, (Solomon, M. \& Rabolt, N., 2009) proposed the circular transaction model of CBB, termed as Consumer Buying Cycles (CBC). The model depicted in Figure 1 has 7 stages of $\mathrm{CBC}$.

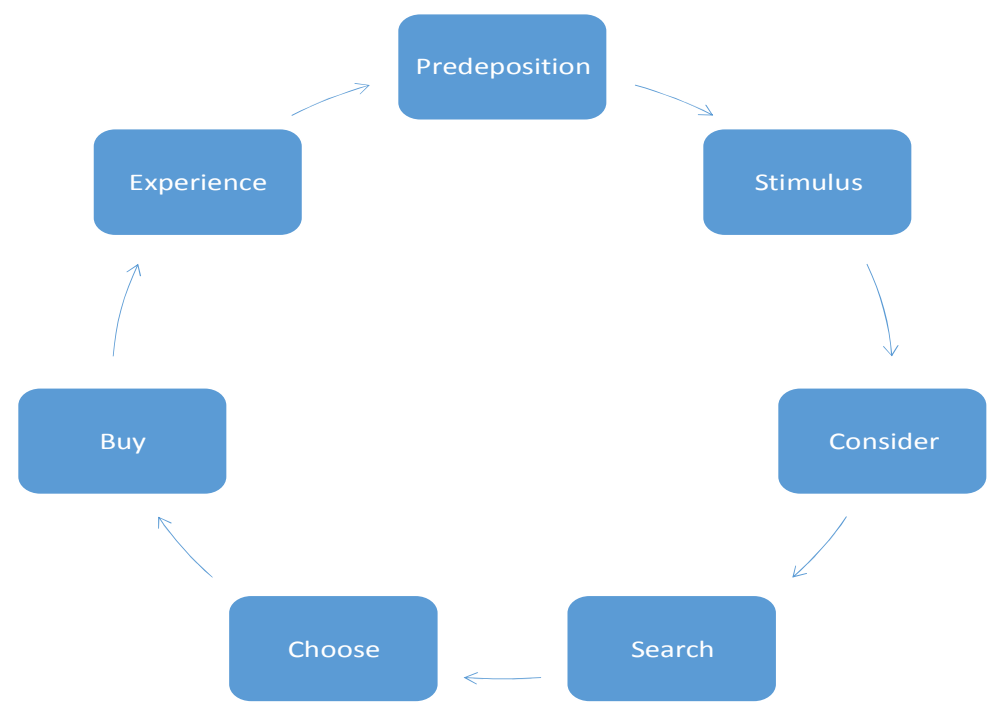

Figure 1: CBC proposed by (Solomon, 2009)

The process of $\mathrm{CBC}$ as stated in Figure 1, designates that in the beginning state, the consumer has no plans of buying any precise product until they identify a convinced stimulus. In the ensuing steps, the buyer contemplates the inevitability of the purchase, before moving to doing exploration to find the most apposite product in rapports of factors (price, place or review by other users), where blogs play the foremost role.

(Evans, D. 2010) gave the CBC influenced by Social Media as mentioned in Figure 2. Figure 2 clearly indicates that the influence of blogs is larger in the beginning stages of the buying process. The users of 
blogs have the opportunity to read about other consumer experiences. This can lead to getting users attention, raising interest for the mentioned product or an actual desire to go and purchase the item.

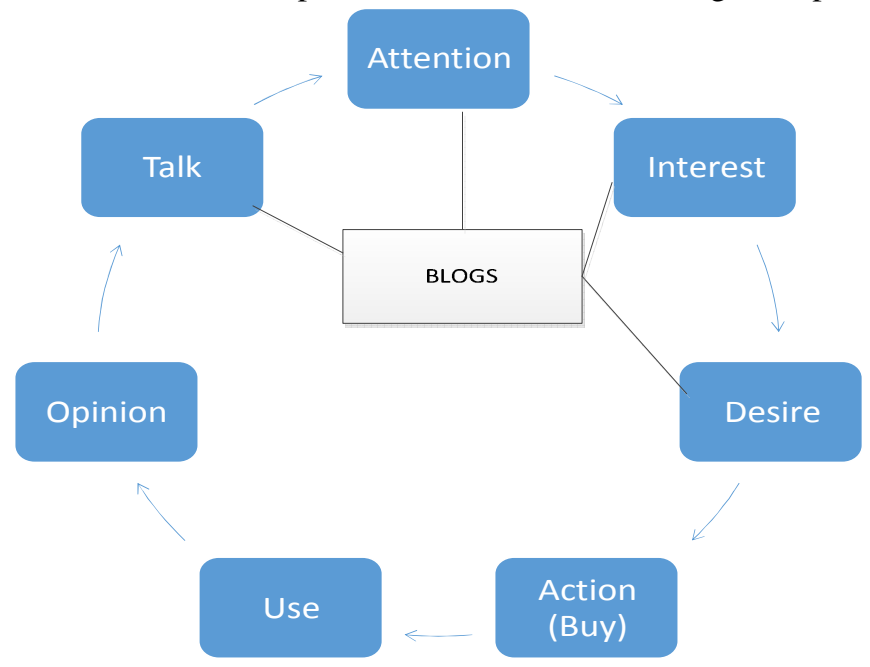

Figure 2: CBC influenced by Blogs

The research conducted in the study presents the stochastic analysis on determination of average number of customers influenced by the blogs. Getting these numbers correctly and putting a superfluous marketing exertion will unquestionably guide many companies who anticipate to use blogs as one of the marketing contrivance. Althoughthree-fourths of marketers planned to increase strategic efforts on social media and social networking sites this year, with $68 \%$ also focusing more on SEO and 63\% on blogs (2013-Mobile-Social-Lead-Shift-Traditional-MediaDigital, 2013), getting average number of customers using blogs and the time they spend per blog will guide them in following ways(44-ways-to-use-a-blog-as-a-small-business-owner, 2010):

- Build Trust, Authority and Credibility

- Market the Business

- Listen to and Engage With Customers and Readers

- Growing Online Presence and Network

The rest of the paper is divided as follows: Section 2 determines the mathematical assumptions of determining "blogging effect" on CBB. The section definesAvgCust $(n)$, average number of blog readers, and, AvgWait $(t)$, average time spend by each reader per blog. Section 3 does the analysis of the outcomes based on the formula developed in Section 2. Section 4 mentions the conclusion of the work.

\section{Mathematical Assumptions}

Using blogs, any new potential customers can be added to the market, and members of subpopulation can consent the market with the parameters portrayed in form of $f(\beta, \gamma, \alpha, \mu)$ as mentioned below: 
- $\quad \beta$ : Sharing rate, defines the rate at which the information is being shared through blog.

- $\gamma$ : Churn rate, rate at which the population depends on blog for an updated information.

- $\quad \alpha$ : Entering rate, rate at which the customers are entering the market.

- $\mu$ : Exiting rate, rate at which the customers are leaving the market.

According to (Kermack, W.O. \& McKendrick, A.G.), there are three subdivisions of the total population of Market, N, as

- $\quad S:$ S represents potential customers

- I: I represents current customers

- $R: R$ represents former customers

Mathematically,

$N=S+I+R(1)$

Introduction of blogs and its usage moves the sub-population over time. The population of potential customers may become current customers or current customers befits former customer clearly signifying that $(S, I, R)$ are dynamic in nature.

It can be observed that the population entering the market becomes the part of "potential customer" population. The number of new potential customers joining the market at any instance of time is:

$\alpha(S+I+R)$

However, the population leaving the market can be part of any of the population and can be represented as $\mu S, \mu I$ and $\mu R$.

\subsection{Usage of $S-I-R$ epidemiological model to determine the Number of potential customer}

$S-I-R$ model is used to compute the theoretical number of people entering the market owing to "blogging effect" in a closed population over time. There is constantly arrival of potential customers entering into the market. For this state, all the three parameters must be encompassed in the model, using the ensuing differential equations:

$\frac{d S}{d t}=-\beta S I+\mu(N-S)=-\beta S I+\alpha(S+I+R)-\mu S$

$\frac{d I}{d t}=\beta S I-\gamma I-\mu I$

$\frac{d R}{d t}=\gamma I-\mu R$

Smearing equations (3), (4) and (5), to estimate $\frac{d N}{d t}$, 
$\frac{d N}{d t}=\frac{d(S+I+R)}{d t}=\frac{d S}{d t}+\frac{d I}{d t}+\frac{d R}{d t}$

Evaluating eq. (6), we observe

$\frac{d N}{d t}=(\alpha-\mu) N$

$\int \frac{d N}{N}=(\alpha-\mu) \int d t$

$\therefore \log N=(\alpha-\mu) t$

$N=e^{(\alpha-\mu) t}$

Based on eq. (8), there can be three possibilities(Srivastava, Riktesh, 2012):

1. Number of customer increases after reading the blogs and market grows exponentially, $\alpha>\mu$

2. Blogs had a neutral affect, $\alpha=\mu$

3. Blogs had a negative effect, $\alpha<\mu$

The objective of the study is to ascertain the stochastic analysis of "blogging effect" on the market expending case 1 .

For estimation of probability of " $n$ " customers from the complete population, $N$, certain assumptions are to be made, which includes,

1. $\Delta t$ is a very small time in which any one of the situation, $S, I$ or $R$ occurs.

2. Case 1 needs to be maintained throughout the study.

3. $\alpha$ is entering rate of consumers into the market and $\mu$ is the exiting rate. Since, case 1 needs to be maintained, $\alpha$ should always be more than $\mu$.

Probability of one customer entering the market $=\alpha \Delta t$

Probability of one customer exiting from the market $=\mu \Delta t$

Probability that no customer entering the market $=1-\alpha \Delta t$

Probability of no customer is exiting from the market $=1-\mu \Delta t$

The probability that there are $n$ customers in the market at any given time $t$ is represented as $P_{n}(t)$.

$$
P(t+\Delta t) \quad\left\{\begin{array}{l}
P_{n(t)}(1-\alpha \Delta t)(1-\mu \Delta t) \\
P_{n+1(t)} \mu \Delta t \\
P_{n-1(t)} \alpha \Delta t
\end{array}\right.
$$

or,

$P(t+\Delta t)=P_{n}(t)(1-\alpha \Delta t)(1-\mu \Delta t)+P_{n+1}(t) \mu \Delta t+P_{n-1}(t) \alpha \Delta t$

$\frac{P_{0}(t+\Delta t)-P_{0}(t)}{\Delta t}=-\alpha P_{n}(t)-\mu P_{n}(t)+\alpha P_{n-1}(t)+\mu P_{n+1}(t)$

For the stable condition, 
$\lim _{\Delta t \rightarrow 0}\left\{\frac{P_{n}(t+\Delta t)-P_{n}(t)}{\Delta t}\right\}=\frac{d}{d t}\left\{P_{n}(t)\right\}=0$

So, eq. (11) becomes

$P_{n-1}(t) \alpha \Delta t-(\alpha+\mu) P_{n}(t)+\mu P_{n+1}(t)=0$

Consider that there is no customer at time $(t+\Delta t)$ in the market, then,

$$
P_{0}(t+\Delta t)=P_{0}(t)(1-\alpha \Delta t)+P_{1}(t) \mu \Delta t
$$

$\frac{P_{n}(t+\Delta t)-P_{n}(t)}{\Delta t}=-P_{0}(t) \alpha+P_{1}(t) \mu$

LHS of eq. (12) becomes

$\lim _{\Delta t \rightarrow 0}\left\{\frac{P_{n}(t+\Delta t)-P_{n}(t)}{\Delta t}\right\}=\frac{d}{d t}\left\{P_{0}(t)\right\}=0$

Eq. (13) can be mentioned as

$P_{1}(t)=(\alpha / \mu) P_{0}(t)$

For $n^{\text {th }}$ values, the eq. (14) can be refurbished as

$\sum_{i=0}^{n} P_{i}(t)=\left\{(\alpha / \mu)^{0}+(\alpha / \mu)^{1}+(\alpha / \mu)^{2}+\ldots \ldots \ldots \ldots . . .(\alpha / \mu)^{n}\right\} P_{0}(t)$

Based on the limiting condition, when $n \rightarrow \infty$, and, ${ }^{\alpha} / \mu<1$, LHS of eq. (15) becomes 1 and RHS of eq. (15) becomes $\left[\frac{1}{(1-\alpha / \mu)}\right] P_{0}(t)$

Rewriting eq. (16)

$1=\left[\frac{1}{(1-\alpha / \mu)}\right] P_{0}(t)$

Eq. (16) can be rewritten as

$P_{n}(t)=(\alpha / \mu)^{n}(1-\alpha / \mu)$

Thus, based on eq. (17), the probability for the presence of " $n$ " customers using blogs at any time " $t$ " can be computed, provided the values of $\alpha$ and $\mu$ are known. The equation for defining the average number of customers using blogs for purchasing can be depicted as, 


$$
\begin{aligned}
& \operatorname{AvgCust}_{(n)}=\sum_{n \rightarrow \infty}^{N} n P_{n}(t) \\
& =\sum_{n \rightarrow \infty}^{N}(\alpha / \mu)^{n}(1-\alpha / \mu) \\
& =(1-\alpha / \mu) \sum_{n \rightarrow \infty}^{N}(\alpha / \mu)^{n} \\
& =(1-\alpha / \mu)\left\{1 \cdot(\alpha / \mu)^{1}+2 \cdot(\alpha / \mu)^{2}+3 \cdot(\alpha / \mu)^{3}+\ldots \ldots \ldots \ldots . . . . . . .(\alpha / \mu)^{n}\right\} \\
& \operatorname{AvgCust}_{(n)}=\frac{(\alpha / \mu)}{(1-\alpha / \mu)} \quad(18)
\end{aligned}
$$

Based on eq. (18), the average waiting time for customer reads the blog is

$\operatorname{AvgWait}(t)=\frac{1}{\mu}\left(\frac{\varnothing}{1-\varnothing}\right)$, where $\varnothing=\alpha / \mu$

\section{Outcomes and Analysis}

As indicated in Section 2, the section portrays the outcomes of the mathematical formulasdeveloped. The number of users in the blogs are taken into contemplation from 3 different marketing blogs expending DataMarket, which is an open data portal that consents to access and explore thousands of publicly available datasets. Table 1 depicts $\alpha$ and $\mu$, based on which $\operatorname{AvgCust}_{(n)}$ is calculated. Table1 also outlines the number of users using blogs, in terms of percentage.

\begin{tabular}{|c|c|c|c|}
\hline $\mathbf{A}$ & $\mathbf{M}$ & $\begin{array}{c}\text { NUMBER OF } \\
\text { CUSTOMERS IN THE } \\
\text { MARKET (ONLINE } \\
\text { CUSTOMERS) }\end{array}$ & $\begin{array}{c}\text { PERCENTAGE OF } \\
\text { CUSTOMERS DUE TO } \\
\text { BLOGGING EFFECT }\end{array}$ \\
\hline 66 & 100 & 7.33 & $11.11 \%$ \\
\hline 82 & 120 & 12.33 & $15.04 \%$ \\
\hline 99 & 140 & 19 & $19.19 \%$ \\
\hline 122 & 160 & 12.33 & $10.11 \%$ \\
\hline 131 & 180 & 89 & $67.94 \%$ \\
\hline 139 & 200 & 19 & $13.67 \%$ \\
\hline 144 & 220 & 21 & $14.58 \%$ \\
\hline 167 & 240 & 7.57 & $4.53 \%$ \\
\hline 181 & 260 & 20.67 & $11.42 \%$ \\
\hline 195 & 280 & 30.11 & $15.44 \%$ \\
\hline 212 & 300 & 26.27 & $12.39 \%$ \\
\hline
\end{tabular}

Table 1: Calculation of AvgCust(n) 
Table 2 illustrates the average time each blogger takes to read the blog content. As revealed in Table 2, the reader reads apiece blog in array of 1 to 10 seconds. The result does not delineates the benevolent of blogs read by the reader and is centered in data collection of 3 dissimilar blogs using DataMarket.

\begin{tabular}{|c|c|c|}
\hline $\boldsymbol{\alpha}$ & $\mathbf{M}$ & $\begin{array}{c}\text { WAITING TIME TO } \\
\text { READ THE BLOG (IN } \\
\text { SECONDS) }\end{array}$ \\
\hline 66 & 100 & 0.073 \\
\hline 82 & 120 & 0.103 \\
\hline 99 & 140 & 0.136 \\
\hline 122 & 160 & 0.077 \\
\hline 131 & 180 & 0.494 \\
\hline 139 & 200 & 0.095 \\
\hline 144 & 220 & 0.095 \\
\hline 167 & 240 & 0.032 \\
\hline 181 & 260 & 0.079 \\
\hline 195 & 280 & 0.108 \\
\hline 212 & 300 & 0.088 \\
\hline
\end{tabular}

Table 2: Calculation of AvgWait(t)

\section{Concluding Remarks}

The study conducted used the model of CBB proposed by (Solomon, M. \&Rabolt, N., 2009). The study evaluates how the information given in blogs by varied sources are taken seriously by the consumers. The outcomes cited in two tables, specifies that the part of blogs on CBB is relatively significant, though the duration of reviews reading by the consumer is quite short. The paper does not suffice any cause for short extent of review reading, but it is well assumed that the spell does not have any much alteration on final buying verdicts. The study aims to be further augment the research on part of blogs on post buying behavior, though, it is witnessed that the consumer go back to the blog after purchase to leave their annotations about the product purchased, its influence on CBB is still unknown.

\section{References}

[1] (Alasilta, A., 2009). "Blogituleetöihin”. Keuruu: OtavanKirjapainoOy. (Google Translation)

[2] (Chui and Manyika, 2011). "Big data: The next frontier for innovation, competition, and productivity", McKinsey Global Institute.

[3] (Evans, D. 2010). "Social Media Marketing. The next generation of business engagement". Indiana: Wiley Publishing, Inc.

[4] (Kermack,W.O. \& McKendrick,A.G.), "A Contribution to the Mathematical Theory of Epidemics", Proceedings of the Royal Society, A Mathematical, Physical and Engineering Sciences, (http://rspa.royalsocietypublishing.org/content/115/772/700.full.pdf+html

[5] (Kotler, P., 2000). "Principles of marketing". Ninth edition. Essex: Prentice Hall. 
[6] (Sergio Zyman,2000), “The end of Marketing as we know it”, HarperBusiness.

[7] (Solomon, M. \& Rabolt, N., 2009). "Consumer Behavior in Fashion”, New Jersey, Prentice Hall.

[8] (Srivastava, Riktesh, 2012), “Analysis Of Job Scheduling Algorithm For An E-Business Model In A Cloud Computing Environment Via GI/G/3/N/K Queuing Model”, International Journal of Advancements in Technology, pp. 215-229, Vol. 3 No. 4.

[9] (2013-Mobile-Social-Lead-Shift-Traditional-Media-Digital, 2013),http://www.emarketer.com/Article/2013-Mobile-Social-Lead-Shift-Traditional-MediaDigital/1009677

[10] (44-ways-to-use-a-blog-as-a-small-business-owner,2010),http://blogforprofit.com/businessblogging/44-ways-to-use-a-blog-as-a-small-business-owner/ 